\title{
Perfil de tutores e coordenadores de cursos EAD da Universidade Federal de Santa Catarina
}

\section{Profile of tutors and coordinators of Distance Education Courses from Federal University of Santa Catarina}

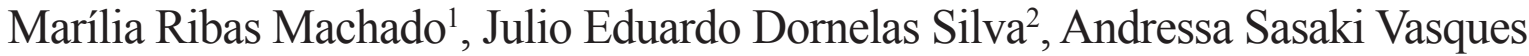 \\ Pacheco ${ }^{3}$, Pedro Antônio de Melo $^{4}$
}

Resumo

O alcance de resultados satisfatórios na educação a distância demanda o uso eficiente de diversos recursos materiais e intangíveis aliados a uma equipe capacitada para atuar nessa modalidade de ensino. Dessa forma, a pesquisa apresentada neste artigo objetivou analisar o perfil de tutores e coordenadores dos polos de apoio presencial localizados nos estados do Paraná, Rio Grande do Sul e Santa Catarina, cujos cursos de graduação a distância estão sob a tutela da Universidade Federal de Santa Catarina. Para atender ao objetivo, a metodologia englobou a aplicação de questionários aos agentes em análise, propiciando dados quantitativos sobre seus perfis. Os resultados apontam que a maior parcela dos coordenadores e tutores analisados são do gênero feminino, com idades entre 36 e 55 anos, possuindo em sua grande maioria especialização, exercendo as funções de tutor, coordenadores dos polos e de ensino, residindo nas mesmas cidades onde os cursos são ofertados e consideram-se de maneira geral, satisfeitos com suas atribuições.

Palavras-chaves: Ensino a distância. Gestão universitária. Perfil. Tutor. Coordenador.

\begin{abstract}
Achieving satisfactory results in distance education requires the efficient use of different materials and intangible assets together with a team trained to act in this type of education. Thus, the research presented in this paper aimed to analyze the profile of tutors and coordinators of classroom support poles located in the states of Parana, Rio Grande do Sul and Santa Catarina, whose undergraduate distance learning courses are under the supervision of the Federal University of Santa Catarina. To meet the goal, the methodology involved the use of questionnaires to the agents in question, providing quantitative data on their profiles. The results show that the largest share of the analyzed coordinators and tutors are female, aged 36 to 55 years, having mostly expertise residing in the same cities where the courses are offered and are considered in general, satisfied with their assignments.
\end{abstract}

Keywords: Distance education. University management. Profile. Tutors. Coordinators.

\footnotetext{
${ }^{1}$ Mestranda do curso de Administração da Universidade Federal de Santa Catarina. E-mail: marilia.ribas9@gmail.com.

${ }^{2}$ Doutorando em Administração pela Universidade Federal de Santa Catarina. Mestre (2013) e Graduado (2011) em Administração pela Universidade Federal de Santa Catarina.

3 Doutora em Engenharia e Gestão do Conhecimento - UFSC. Professora do Programa de Pós-graduação em Administração e do Programa de Pós-graduação em Administração Universitária.

${ }^{4}$ Doutor em Engenharia de Produção e Sistemas, pela Universidade Federal de Santa Catarina, e pós-doutorado em Educação Superior, pelo Instituto Internacional para a Educação Superior na América Latina e o Caribe - IESALC, da Unesco. É Doutor Honoris Causa, pela Honorable Academia Mundial de Educación - HAME (2012).
} 


\section{Introdução}

A educação a distância (EaD) é um tema cada vez mais estudado na academia, especialmente por sua ascensão ter ocorrido a partir do século XX. De acordo com Moore e Kearsley (2007), a EaD possui como característica a separação geográfica entre alunos e professores na maior parte do tempo em que aprendem e ensinam com a utilização de tecnologias da informação e comunicação indicadas.

$\mathrm{Na}$ tentativa de clarificar a procura pelo modelo de ensino referido, pode-se apurar que a busca para essa modalidade deu-se em virtude do modelo social atual, em que as pessoas possuem cada vez menos tempo para se dedicarem aos estudos, priorizando muitas vezes adquirir outros conhecimentos que não teóricos praticados na academia. Dentre os fatores que podem ser elencados a fim de elucidar os motivos pelos quais cada vez mais pessoas optam por esta modalidade de ensino estão (1) a falta de disponibilidade de tempo, (2) o não deslocamento de suas residências até a instituição de ensino, (3) a incompatibilidade de horários, além do (4) difícil acesso ao ensino presencial. Em uma pesquisa realizada pela Associação Brasileira de Educação a Distância (ABED), Souza (2012) indica os motivos pelos quais os alunos optam pela educação a distância:

- Os acadêmicos querem apenas ter um diploma de nível superior, justificando que será importante para realizar concursos públicos que exijam a diplomação mínima de graduado;

- Os acadêmicos desejam entrar no mercado de trabalho, mas devido a sua competitividade é de exigência mínima a graduação para pleitear um cargo com uma razoável remuneração;

Para conseguir atender a essa demanda recente de educação, é necessário uma estrutura de ensino bem articulada entre recursos materiais e intangíveis, associada a uma extensa equipe de professores, coordenadores e tutores, tanto na instituição matriz, quanto nos polos presenciais distribuídos pelo interior do Brasil. Nesse sentido, surgiu como problema de pesquisa qual o perfil dos tutores e coordenadores de EaD coordenados pela UFSC, nos Cursos de Administração, Ciências Contábeis e Ciências Econômicas?.

\section{Fundamentação Teórica}

Nesta seção são abordados os conceitos que proporcionam o embasamento teórico em relação ao tema $\mathrm{EaD}$, seu histórico, a EaD no Brasil, além de descrever brevemente os impactos que essa modalidade pode proporcionar às pessoas bem como a sinalização da educação como propulsora do desenvolvimento.

\section{Conceituação da EaD}

A literatura possui uma gama de definições para ensino a distância, dentre os quais Lobo Neto (2001), que discorre que a EaD deve ser entendida no contexto mais amplo da educação e constituir-se emum objeto de reflexão crítica, capaz de fundamentá-la. Pretto (2003) acredita que o desafio da EaD é o mesmo desafio da educação como um todo e sua discussão precisa estar inserida nas discussões teóricas da educação, bem como das políticas públicas. Alonso (2016) afirma que a EaD não é algo isolado da educação em geral, pois liga-se à ideia de democratização e facilitação do acesso à escola e não a ideia de suplência ao ensino regular, nem tampouco à implantação de sistemas provisórios. Ainda em relação a esta modalidade de ensino, Maia e Mattar (2007), discorrem que a Educação a Distância atualmente é praticada nos mais variados setores. Ela é usada na Educação Básica, no Ensino Superior, em universidades abertas, universidades virtuais, treinamento governamentais, cursos abertos, livres.

O que pode-se constatar com a conceituação de educação a distância exposta pelos autores é que as definições estão interligadas, visto que é uma modalidade de ensino importante e necessária para a democratização da educação. Ademais, a oferta de variados cursos é cada vez mais crescente e os 
cursos superiores de educação a distância apresentam diplomas similares aos diplomas dos cursos oferecidos pelas instituições de ensino superior que possuem a modalidade presencial, fornecendo ao estudante que opta pelo ensino a distância mais essa vantagem.

\section{Surgimento da EaD}

Desde o século XIX a educação a distância passou a ser institucionalizada principalmente entre alguns países desenvolvidos. Em 1829 na Suécia foi inaugurado o Instituto Líber Hermondes, que possibilitou a mais de 150.000 pessoas realizarem cursos através da Educação a Distância; também como exemplo, em 1856 em Berlim, a Sociedade de Línguas Modernas patrocinou alguns professores para ensinarem Francês por correspondência. (ALVES, 2011).

Porém, o século XX foi considerado o auge da expansão da educação a distância no mundo, com uma intensa presença em universidades e nos cenários econômicos globais. Nunes (2009, p. 3) elenca algumas universidades que foram criadas nesse período:

- Open University, no Reino Unido;

- FernUniversität, na Alemanha; e

- Universidad Estatal a Distancia, na Costa Rica.

Em Belloni (2008, p. 9) encontra-se que, segundo Peters (1983), “a EaD surgiu em meados do século passado com o desenvolvimento dos meios de transporte e comunicação (trens, correio), cuja regularidade e confiabilidade permitiram o aparecimento das primeiras experiências de ensino por correspondência na Europa e nos Estados Unidos".

Ainda de acordo com Belloni (2006), o professor (ensinante) deve assumir as seguintes funções na educação a distância, tais como:

- Professor formador (ensinante), que orienta o estudo e a aprendizagem ensinando a pesquisar e processar informação;
- Conceptor e realizador de cursos e matérias, prepara os planos de estudos, currículos e programas, seleciona conteúdos, elabora textos para formar a base do curso;

- Professor pesquisador (ensinante), pesquisa e se atualiza em sua disciplina;

- Professor tutor (ensinante) orienta o aprendente em seus estudos relativos á disciplina pela qual será responsável;

- Tecnólogo educacional (designer ou pedagogo especialista em tecnologias intelectuais, a função é nova, o que explica a dificuldade terminológica), responsável pela adequação aos suportes técnicos a serem utilizados na produção de materiais;

- Professor como "recurso" assegura uma espécie de "balcão" de respostas as dúvidas mais frequentes dos estudantes em relação aos conteúdos;

- Monitor coordena e orienta, sua função se relaciona menos com o conhecimento dos conteúdos e mais com sua capacidade de liderança, geralmente é uma pessoa da comunidade, formada para esta função, de caráter mais social do que pedagógico.

A tutoria é responsável por construir conhecimentos e ajudar nas dificuldades promovendo os estudos e o auto-estudo. Além disso, a tutoria tem a incumbência de "orientar o aluno e esclarecer dúvidas relativas ao estudo da disciplina pela qual é responsável", como apresentado por Barros (2002, p. 15).

Por fim, o que podemos notar é que a educação a distância é fundamental para o desenvolvimento e aprimoramento intelectual de uma nação. Essa oportunidade de desenvolvimento deve ser entendida comoum avanço para a educação nacional e não deveria ser compreendida como um ensino instrumental somente, onde há a possibilidade de lucrar frente às demandas educacionais da população. 


\section{Educação a distância no Brasil}

No Brasil, a educação a distância tomou forma principalmente por volta do século XX, na época por volta de 1904 escolas internacionais que eram instituições privadas ofereciam cursos pagos, por correspondência. Além desses estímulos, o SENAC com o desenvolvimento de estudo radiofônicos e as universidades abertas contribuíram para que em anos seguintes a educação a distância no Brasil pudesse ser desenvolvida e aperfeiçoada.

Em correlação acerca do desenvolvimento da educação a distância no Brasil, Marques (2004 apud COSTA; FARIA, 2008) relata que em 1934, o Instituto Monitor iniciou suas atividades e em 1939 o Instituto Universal Brasileiro iniciou suas atividades em São Paulo. Ainda sobre o progresso do ensino a distância, Alves (2009) a partir de 1937, ano que surgiu o Serviço de Radiodifusão Educativa do Ministério da Educação, foram criadas inúmeras iniciativas com o objetivo de transmissão do saber. $\mathrm{O}$ autor ainda destaca algumas iniciativas, tais como:

- Criação da Escola Rádio-Postal, A Voz da Profecia, criada pela Igreja Adventista em 1943;

- SENAC desenvolveu no Rio de Janeiro e em São Paulo a Universidade do Ar, que em 1950, já atingia 318 localidades.

As primeiras experiências de $\mathrm{EaD}$ ocorreram no século XX, para preencher as lacunas dos sistemas de ensino formais quanto a aspectos de profissionalização e, mais especificamente, da aprendizagem de ofícios. (GIUSTA; FRANCO, 2003). Sob a ótica da normalização da EAD, o marco cronológico deu-se em 1996, quando a Lei $n^{\circ}$ 9.394/96 “oficializa a era normativa da educação a distância no Brasil pela primeira vez, como modalidade válida e equivalente para todos os níveis de ensino. Pela primeira vez, na história da legislação ordinária, o tema da $\mathrm{EaD}$ se converte em objeto formal." Marques (2004 apud COSTA; FARIA, 2008, p. 4).
Em suma, segundo González (2005, p. 33) é possível compreender a Educação a Distância como uma "estratégia desenvolvida por sistemas educativos para oferecer educação a setores ou grupos da população que, por razões diversas, têm dificuldade de acesso a serviços educativos regulares".

Corroborando com o exposto acima, a EaD deve ser reconhecida como um sistema de ensino comum a qualquer outro, que é responsável por ampliar o acesso ao ensino superior principalmente levando em consideração suas dificuldades e oportunidades.

\section{Histórico EAD (UAB) no Brasil}

O Sistema Universidade Aberta do Brasil (UAB) é um sistema integrado entre universidades públicas, sendo considerada uma importante iniciativa para inclusão de jovens, com difícil acesso a formação universitária.

O sistema foi oficializado pelo decreto $\mathrm{N}^{\circ} 5.800$ de 8 de junho de 2006, que determina segundo o artigo $1^{\circ}$ que:

\begin{abstract}
Art. $1^{\circ}$ Fica instituído o Sistema Universidade Aberta do Brasil - UAB, voltado para o desenvolvimento da modalidade de educação a distância, com a finalidade de expandir e interiorizar a oferta de cursos e programas de educação superior no País. Parágrafo único. São objetivos do Sistema UAB: I oferecer, (prioritariamente, cursos de licenciatura e de formação inicial e continuada de professores da educação básica;[...] IV- ampliar o acesso à educação superior pública; [...]. (BRASIL, 2006).
\end{abstract}

Em relação ao credenciamento de instruções para oferta de oferta de cursos e programas na modalidade a distância, foi publicado o decreto $\mathrm{N}^{\mathrm{o}}$ 5.622, de 19 de Dezembro de 2005, vide lei 9.394, de 20 de dezembro de 1996, que estabelece as diretrizes e bases da educação nacional segundo o artigo $12^{\circ}$ que:

Art. 12. O pedido de credenciamento da instituição deverá ser formalizado junto ao órgão responsável, mediante o cumprimento dos seguintes requisitos: VI - projeto pedagógico para os cursos e programas que serão ofertados na modalidade a distância; 
[...] VII- garantia de corpo técnico e administrativo qualificado; X - descrição detalhada dos serviços de suporte e infraestrutura adequados à realização do projeto pedagógico, relativamente a: a) instalações físicas e infraestrutura tecnológica de suporte e atendimento remoto aos estudantes e professores; $b$ ) laboratórios científicos, quando for o caso; c) polo de apoio presencial é a unidade operacional, no País ou no exterior, para o desenvolvimento descentralizado de atividades pedagógicas e administrativas relativas aos cursos e programas ofertados a distância; d) bibliotecas adequadas, inclusive com acervo eletrônico remoto e acesso por meio de redes de comunicação e sistemas de informação, com regime de funcionamento e atendimento adequados aos estudantes (BRASIL, 2005).

Segundo Litto e Formiga (2009), em relação a oferta da EaD, a alternativa para atendimento às demandas por educação superior no país, contribuirá para o enfrentamento de um cenário nacional de assimetrias educacionais, seja em relação à oferta de cursos superiores, seja em relação às possibilidades de oferta de educação continuada ao longo da vida.

Desse modo, funciona como um eficaz instrumento para a universalização do acesso ao ensino superior e para a requalificação do professor em outras disciplinas, fortalecendo a escola no interior do Brasil, minimizando a concentração de oferta de cursos de graduação nos grandes centros urbanos e evitando o fluxo migratório para as grandes cidades.

Os cursos oferecidos pela UAB são baseados nas estruturas de polos. Para que seja possível oferecer um curso na EaD é necessário que se tenha um polo de apoio presencial nas cidades ou próximos as cidades que serão ofertados os cursos. De acordo com o portal da CAPES (COORDENAÇÃO DE APERFEIÇOAMENTO DE PESSOAL DE NÍVEL SUPERIOR, 2015), o polo é uma estrutura acadêmica de apoio pedagógico, tecnológico e administrativo às atividades de ensino e aprendizagem dos cursos e programas de $\mathrm{EaD}$ de responsabilidade das instituições públicas de ensino superior.

\section{Possíveis impactos da Educação a Distância}

É possível considerar que a educação a distância é conceituada como uma das formas mais democráticas de modalidades de educação, pois é capaz de atender a diversas pessoas simultaneamente. A educação aberta atende a vários propósitos. Do indivíduo que procura sua primeira qualificação na educação superior ao indivíduo aposentado que busca uma forma de educação continuada e engajamento social. (SANTOS, 2009).

Ainda conforme Santos (2009, p. 291). Ainda em relação ao contexto da educação a distância, pode-se dizer que a educação a distância proporciona oportunidades iguais a indivíduos que vivem em locais mais distantes ou de difícil acesso à educação tradicional.

A oportunidade de obter o aprendizado sem sair de casa é a forma explícita da democracia no processo de aprendizagem. Oportunizar essa formação é de alguma maneira atender as necessidades de pequenas cidades localizadas geralmente no interior dos estados, possibilitando o mesmo conhecimento dos alunos de modalidades presenciais.

Nunes (1994 apud ALVES, 2011, p. 84) defende que a EaD constitui um recurso de incalculável importância para atender grandes contingentes de alunos, de forma mais efetiva que outras modalidades e sem riscos de reduzir a qualidade dos serviços oferecidos em decorrência da ampliação da clientela atendida. Por este motivo, para que a educação disseminada seja inovadora e de qualidade, faz-se necessário um aparato tecnológico para que a comunicação e o processo de ensino sejam eficientes quando forem requisitados.

As Tecnologias da Informação e Comunicação (TICs), conforme corrobora Santos (2009), relativizaram os conceitos de espaço geográfico e tempo, reduzindo virtualmente as distâncias globais e otimizando o tempo gasto para acessar o vasto acervo da produção intelectual da humanidade. 
Em concordância, essa nova modalidade de ensino demanda muita dedicação e esforço dos alunos, visto que o processo de auto-estudo está intimamente ligado ao seu desempenho, uma vez que encontrará seus professores apenas algumas vezes no semestre. Por este motivo, faz-se necessário o total engajamento do aluno com as disciplinas e com os materiais disponibilizado por meio das TICs.

Conforme Silva (2004) declara que a aprendizagem autônoma facilita e engrandece o processo de aprendizagem, uma vez que só aprendemos o que desejamos; o que é imposto memorizamos e posteriormente o desprezamos, porém no ensino a distância é condição essencial para que o ensino seja consolidado. $\mathrm{O}$ autor ainda manifesta que na aprendizagem autônoma, os erros são contribuições para agregarem novos conhecimentos e, mediante descobertas, os alunos identificarem seus erros sendo conduzidos aos acertos e ao crescimento de novas aprendizagens.

Conforme Moran e Valente (2011), as universidades e organizações educacionais, em todos os níveis, precisam experimentar e avançar com coragem rumo à integração do presencial com o virtual, garantindo a aprendizagem significativa de qualidade. De acordo com Santos (2009), seguindo o modo de produção de sociedade do conhecimento, em breve é possível que não se façam mais distinções entre formação inicial e formação continuada, uma vez na EaD o método não distingue do conteúdo.

\section{Educação para o desenvolvimento}

A educação é a palavra que define o desenvolvimento por proporcionar o acesso igualitário de direitos e a ascensão socioeconômica de classes sociais menos privilegiadas, ou seja, a educação pode promover empoderamento de todos que a adquirem.

Conforme Cunha(1986), a ascensão ou descensão do indivíduo estará condicionada à sua educação, ao seu nível de instrução, e não mais ao nascimento ou à fortuna que dispõe. Em correlação ao papel fundamental da educação perante a sociedade Foracchi e Pereira (1978) defendem que a educação desempenha funções de controle social conservador ou inovador de acordo com a orientação geral do sistema global onde se realiza.

Entretanto, através da educação, podemos de saída compreender o que é o poder na sociedade, iluminando as relações de poder que a classe dominante torna obscuras. Também podemos nos preparar e participar de programas para mudar a sociedade (FREIRE; SHOR, 2013). Santos (1970) argumenta que não se pode atingir o desenvolvimento somente pela educação e mesmo esta mão tem maior sucesso se toda uma gama de ações econômicas, de saúde, de vida social não forem deflagradas em simultaneidade.

Por este motivo, faz-se necessário analisar os diversos sistemas da sociedade de maneira geral, uma vez que a educação poderá não ser a única determinante no processo de desenvolvimento, de maneira a estabelecer uma consonância entre todos os sistemas da sociedade em relação ao papel da educação como ampliação do desenvolvimento. Nota-se uma relação indireta entre os discursos dos autores, a educação por vezes é tratada como um investimento social, que serve como ferramenta de controle social, porém em determinado momento, a dimensão educação também traça uma linearidade com a necessidade de investimento econômico, visto que somente por meio da união destes dois fatores, sociais e econômicos, o desenvolvimento poderá alcançar seu papel efetivo.

Ainda em concordância, a união de fatores condicionantes para o acesso da educação, Santos (1970), discorre que não é possível que se espere todo o progresso como decorrência da educação. Também não será certo, que se deixe a educação como processo isolado, desarticulado das metas econômicas da sociedade.

Por fim, pode-se perceber que inevitavelmente para que haja desenvolvimento, é necessário que a educação seja vista como uma alternativa de 
investimento, porém essa alternativa não deve ser vista como a única capaz de proporcionar o desenvolvimento, uma vez que as dimensões de saúde e econômicas agindo em conjunto em conformidade podem proporcionar o verdadeiro desenvolvimento social e econômico de uma população.

\section{Metodologia}

Esta pesquisa classifica-se como descritiva e quantitativa, antecipada de uma busca bibliográfica. Vergara (2000) salienta que um estudo descritivo expõe as características do universo ou população observada, sem se preocupar com a explicação a respeito do que se escreve, embora sirva para isso e possibilite o estabelecimento de correlações. $\mathrm{O}$ estudo tem como intuito descrever o perfil dos tutores e coordenadores de EaD da UFSC nos cursos de Administração, Ciências Contábeis e Ciências Econômicas. Com o objetivo de tornar a leitura facilitada, neste estudo o termo coordenador de ensino e coordenador de polo são correlatos, assim como o termos tutor presencial e tutor de polo são correspondentes. Nessa linha, considerando o que Gil (2008) propõe quanto aos objetivos, a pesquisa caracteriza-se como descritiva, pois foi possível descrever além do perfil, descrever de maneira geral a satisfação dos entrevistados com suas funções.

Santos e Clos (1998) definem estudos quantitativos como métodos que se apropriam da análise estatística para o tratamento dos dados. Segundo Moresi (2003), as pesquisas quantitativas são projetadas para medidas quantificáveis e precisas. Esta técnica de pesquisa é usada quando se quer determinar o perfil de um grupo de pessoas, baseando-se em características que elas têm em comum. Ainda com o propósito de conceituar o modelo de pesquisa utilizado no estudo, de acordo com Trivinos (1995), a pesquisa quantitativa faz descrições do que precisa ser conhecido e que se tem interesse em conhecer. A pesquisa quantitativa foi usada com o objetivo de coletar dados sobre o perfil dos tutores e coordenadores coordenados pela UFSC nos cursos de Administração, Ciências
Contábeis e Ciências nos estados do Paraná, Rio Grande do Sul e Santa Catarina. A justificativa pela escolha desses estados deu-se em virtude da acessibilidade das informações devido aos estados pertencerem na região Sul do país.

O levantamento bibliográfico observado na classificação de Gil (2008) ocorreu nessa pesquisa durante a realização da fundamentação teórica, embasada na conceituação, surgimento, histórico da educação a distância no Brasil, além dos possíveis impactos advindos da educação a distância, bem como a educação como agente causador do desenvolvimento.

Aaker, Kumar e Day (2001) entendem que os métodos de coleta de dados podem ser classificados, inicialmente, em relação ao uso de fontes primárias ou secundárias. No caso desta pesquisa, os dados são primários por não estarem previamente disponíveis, tendo sido coletados diretamente entre os meses de maio e junho de 2015. Para a coleta destes dados, foi aplicado um questionário com perguntas abertas e de múltipla escolha, desenvolvido no Google Docs para a geração de um link eletrônico de acesso. Considerando que a análise seria direcionada a pessoas geograficamente distantes, esse formato tornou-se eficiente no momento da obtenção das informações e andamento da pesquisa. Marconi e Lakatos (2003, p. 201), complementam que "o questionário é um instrumento de coleta de dados, constituído por uma série de perguntas, que devem ser respondidas por escrito e sem a presença do entrevistador".

O questionário foi aplicado a uma população caracterizada por coordenadores e tutores dos polos dos cursos de graduação em Administração, Ciências Contábeis e Ciências Econômicas em cidades do Paraná, Rio Grande do Sul e de Santa Catarina, totalizando 62 agentes. Foram obtidas 30 respostas, o que representa $48,39 \%$ do total dos envolvidos. Nas ideias de Barbetta (2002), essa representatividade constitui o conjunto dos elementos que se deseja estudar. 


\section{Resultados e Análise dos Dados}

$\mathrm{Na}$ análise em relação à pesquisa realizada foi possível obter 30 respostas, têm-se os seguintes resultados:

Gráfico 1- Perfil dos entrevistados.

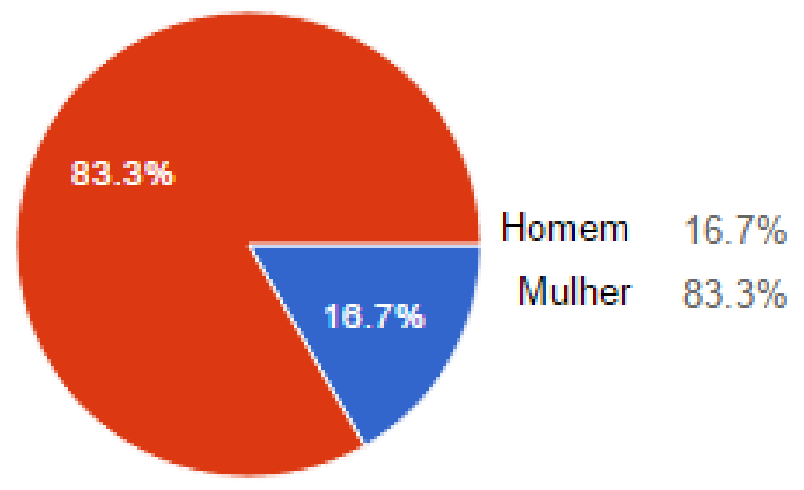

Fonte: Elaborado pelos autores.

Dentre 30 respondentes verificou-se que: 25 pessoas, $(83,3 \%)$, são do sexo feminino, enquanto apenas 5 pessoas, (16,7\%), são do sexo masculino.

Gráfico 2 - Faixa etária dos entrevistados

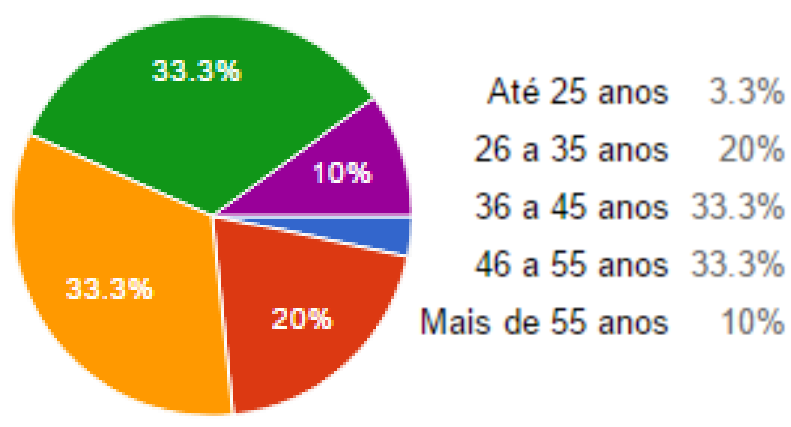

Fonte: Elaborado pelos autores.

Em relação à faixa etária dos entrevistados, verificou-se que: 20 entrevistados, $(66,6 \%)$, possuem idade entre 36 e 55 anos, ademais, 6 entrevistados, (20\%), possuem idade entre 26 a 35 anos. Também foi possível verificar que 3 respondentes, (10\%), têm idade superior a 55 anos e apenas 1 entrevistado, $(3,3 \%)$, tem idade igual ou inferior a 25 anos.
Gráfico 3 - Nível de escolaridade dos entrevistados

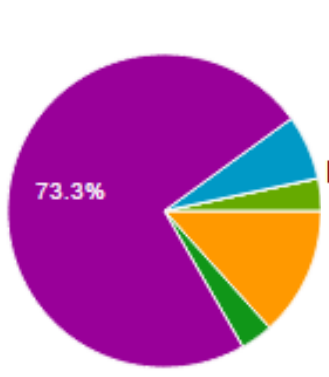

Ensino Médio completo $\quad 0 \%$

Ensino Médio incompleto $\quad 0 \%$

Ensino Superior completo $13.3 \%$

Ensino Superior incompleto $3.3 \%$

Especialização $73.3 \%$

Mestrado $\quad 6.7 \%$

Doutorado $\quad 0 \%$

Fonte: Elaborado pelos autores.

Outros $\quad 3.3 \%$

Dentre os entrevistados, em relação ao nível de escolaridade, 22 entrevistados, (73,3\%), possuem especialização. Além disso, 4 respondentes, $(13,3 \%)$, tem o ensino superior completo, enquanto que 1 entrevistado, $(3,3 \%)$, possui ensino superior incompleto, no mesmo tempo que 2 respondentes, $(6,7 \%)$, possuem mestrado, apenas 1 pessoa, $(3,3 \%)$ está com o doutorado em curso.

Gráfico 4 - Entrevistados que trabalham em sua área de formação

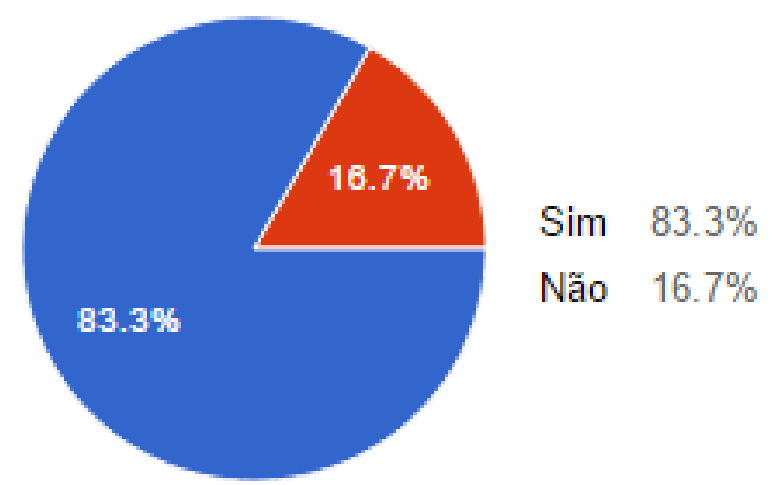

Fonte: Elaborado pelos autores.

Com relação à porcentagem dos entrevistados que trabalham em sua área de formação verificou-se que: 25 dos entrevistados, $(83,3 \%)$, afirmam que trabalham em sua área de formação, outras 5 pessoas, (16,7\%), afirmaram que não trabalham na sua área de formação

Em seguida, os entrevistados foram questionados sobre a sua função desempenhada atualmente no polo $\mathrm{EaD}$, além de qual polo de apoio presencial fazem parte e ainda a cidade na qual residem. 
Quadro 1 Função dos entrevistados, polo presencial de trabalho e cidades que residem.

\begin{tabular}{|c|c|c|c|}
\hline Estado & Função Desempenhada & Cidade do Polo & Cidade que Reside \\
\hline \multirow{4}{*}{ PR } & Tutor Presencial & Cidade Gaúcha & Cidade Gaúcha \\
\hline & Coordenador de Ensino & Cruzeiro do Oeste & Cruzeiro do Oeste \\
\hline & Tutor Presencial & Cruzeiro do Oeste & Cruzeiro do Oeste \\
\hline & Tutor Presencial & Foz do Iguaçu & Foz do Iguaçu \\
\hline \multirow{13}{*}{$\mathrm{RS}$} & Coordenador de Ensino & Paranavaí & Paranavaí \\
\hline & Coordenador de Ensino & Hulha Negra & Bagé \\
\hline & Tutor Presencial & Hulha Negra & Bagé \\
\hline & Coordenador de Ensino & São Francisco de Paula & São Francisco de Paula \\
\hline & Tutor Presencial & São Francisco de Paula & São Francisco de Paula \\
\hline & Coordenador de Ensino & Sapucaia do Sul & Sapucaia do Sul \\
\hline & Tutor Presencial & Sapucaia do Sul & Sapucaia do Sul \\
\hline & Coordenador de Ensino & Seberi & Seberi \\
\hline & Tutor Presencial & Seberi & Seberi \\
\hline & Coordenador de Ensino & Tapejara & Tapejara \\
\hline & Tutor Presencial & Tapejara & Tapejara \\
\hline & Coordenador de Ensino & Tio Hugo & Tio Hugo \\
\hline & Tutor Presencial & Tio Hugo & Tio Hugo \\
\hline \multirow{13}{*}{$\mathrm{SC}$} & Coordenador de Ensino & Vila Flores & Vila Flores \\
\hline & Coordenador de Ensino & Blumenau & Blumenau \\
\hline & Tutor Presencial & Blumenau & Blumenau \\
\hline & Coordenador de Ensino & Braço do Norte & Braço do Norte \\
\hline & Tutor Presencial & Braço do Norte & Braço do Norte \\
\hline & Coordenador de Ensino & Campos Novos & Campos Novos \\
\hline & Coordenador de Ensino & Chapecó & Chapecó \\
\hline & Tutor Presencial & Concórdia & Concórdia \\
\hline & Coordenador de Ensino & Florianópolis & São José \\
\hline & Tutor Presencial & Florianópolis & Florianópolis \\
\hline & Coordenador de Ensino & Itapema & Itapema \\
\hline & Tutor Presencial & Itapema & Porto Belo \\
\hline & Tutor Presencial & Laguna & Laguna \\
\hline
\end{tabular}

Fonte: Elaborado pelos autores.

Nesse sentido, de acordo com as respostas obtidas pelos entrevistados, pode-se verificar que grande parte dos entrevistados são pertencentes aos estados do Rio Grande do Sul e Santa Catarina, possuindo a menor participação o estado do Paraná. 
Gráfico 5- Função desempenhada pelos entrevistados

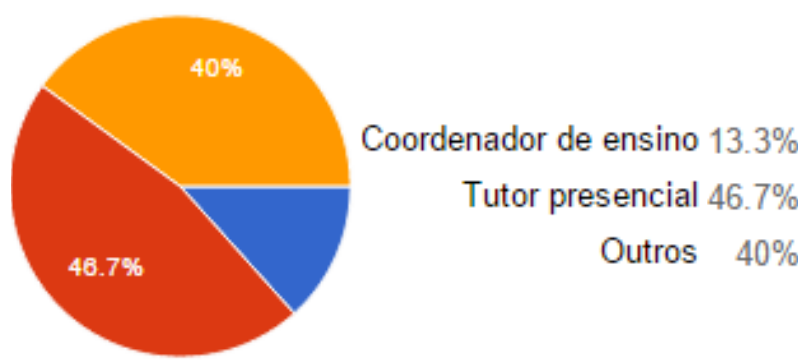

Fonte: Elaborado pelos autores.

Quanto à função desempenhada atualmente pelos entrevistados, 14 pessoas, (46,7\%), afirmaram exercer a função de tutor presencial. Enquanto que apenas 4 entrevistados, (13,3\%), exercem a função de coordenador de ensino. Os outros 12 entrevistados, (40\%), afirmam possuir outras ocupações dentro da instituição.

Gráfico 6 - Experiência dos entrevistados para exercer atual atividade

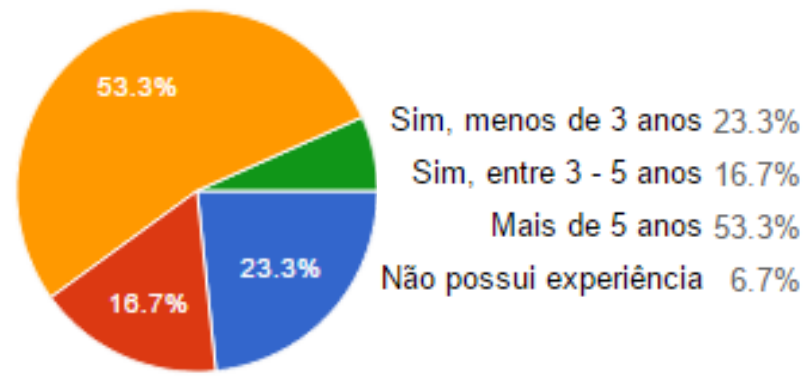

Fonte: Elaborado pelos autores.

Em Relação a experiência dos entrevistados para exercer atual função, 16 respondentes, $(53,3 \%)$, afirmaram possuir mais de 5 anos de experiência, 7 entrevistados, $(23,3 \%)$, afirmaram que possuem menos de 3 anos de experiência, enquanto que 5 entrevistados, (16,7\%), afirmaram que possuem entre 3 a 5 anos de experiência na atividade e apenas 2 respondentes $(6,7 \%)$ afirmaram que não possuem experiência para o desempenho da atual função.
Gráfico 7 - Tempo de serviço dos entrevistados na atual função

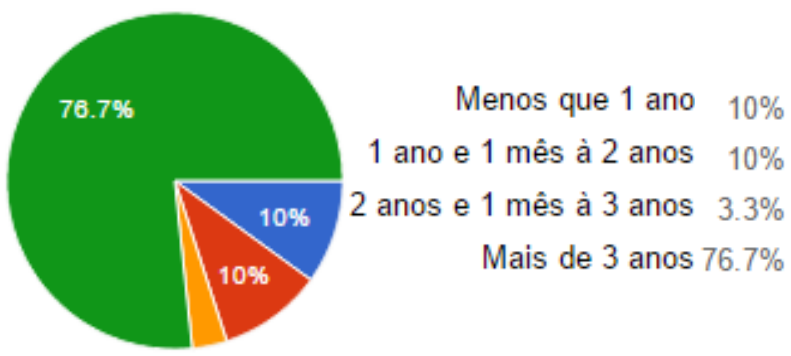

Fonte: Elaborado pelos autores.

De acordo com o tempo de serviço desempenhando a mesma atividade, 23 entrevistados (76,7\%), afirmaram estar na função há um período superior a 3 anos, além do que, 3 respondentes, (10\%), alegaram ter um tempo de serviço inferior a 1 ano e outros 3 respondentes, (10\%), afirmaram possuir tempo de serviço de 1 ano e 1 mês à 2 anos, enquanto que apenas 1 entrevistado, (3,3\%), afirmou que possui tempo de serviço de 2 anos e 1 mês à 3 anos.

Gráfico 8 - Satisfação dos entrevistados em relação a sua função

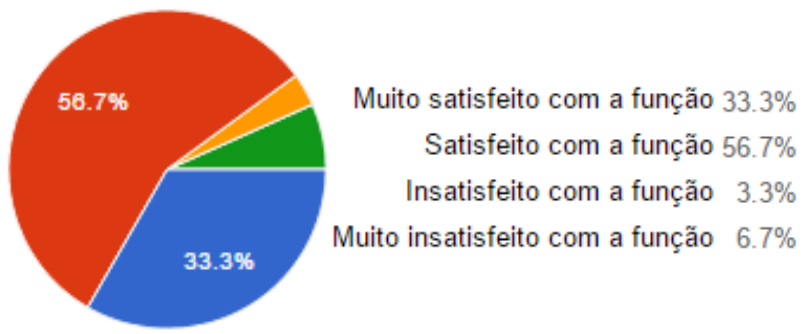

Fonte: Elaborado pelos autores.

Em correlação à satisfação dos entrevistados com sua atual função, verificou-se um alto índice de satisfação entre os tutores e os coordenadores. Dos 30 respondentes, 27 respondentes, (90\%), afirmaram estar muito satisfeitos ou satisfeitos com suas atividades, em contraponto a isso, pode-se observar que apenas 3 entrevistados (10\%) estão insatisfeitos ou muito insatisfeitos com sua atual atividade. 


\section{Conclusão}

A partir das análises quantitativas apresentadas na análise desta pesquisa, é possível fazer algumas considerações finais sobre o estudo. O propósito desta pesquisa foi analisar o perfil dos tutores e coordenadores de $\mathrm{EaD}$ dos cursos de Administração, Ciências Contábeis e Ciências Econômicas da Universidade Federal de Santa Catarina. Os aspectos materiais detectados por meio do questionário revelaram que a maioria dos coordenadores e tutores dos polos de apoio presencial são do sexo feminino com faixa etária que varia de 36 até 55 anos, além disso, a maioria dos entrevistados possui especialização. Em relação ao grau de satisfação com suas atividades, pode-se considerar que a maioria dos entrevistados encontra-se satisfeita com sua função. Ademais, com relação a função exercida, é possível informar que dentre os entrevistados, metade correspondem a tutores presenciais e os outros quinze exercem o papel de coordenador de ensino nos polos e apenas quatro dentre os entrevistados residem em cidade diferente da qual o polo está instalado, facilitando o deslocamento por entre as cidades, podendo assim o tutor e o coordenador dedicar-se com maior afinco para demandas com um nível de importância superior.

Pode-se perceber que com o advento da educação a distância para as regiões elencadas no decorrer do trabalho, foi um fator determinante para a promoção do desenvolvimento das regiões, prova disso é a expansão da modalidade de ensino a distância nas mais diversas regiões do país. Portanto, após as análises e interpretação dos dados, pode-se concluir que o presente estudo teve seus objetivos alcançados, uma vez que foi possível descrever o perfil dos tutores e coordenadores dos polos, além de ter sido possível analisar de maneira geral a satisfação dos entrevistados com suas funções.

\section{Referências}

AAKER, D. A.; KUMAR, V.; DAY, G. S. Pesquisa de marketing. São Paulo: Atlas, 2001.
ALONSO, K. M. A avaliação e a avaliação na educação a distância: algumas notas para reflexão. Disponível em: <https://www.nescon. medicina.ufmg.br/biblioteca/imagem/2510.pdf $>$. Acesso em: 2 fev. 2016.

ALVES, J. R. M. A história da EaD no Brasil. In: LITTO, F.; FORMIGA, M. (Org.). Educação à distância: o estado da arte. São Paulo: Pearson Education do Brasil, 2009. p. 9-13.

ALVES, L. Educação a distância: conceitos e história no Brasil e no mundo. RBAAD: Revista da Associação Brasileira de Educação A Distância, Rio de Janeiro, v. 10, p. 84-92, 2011. Disponível em: $\quad<$ http://www.abed.org.br/revistacientifica/ Revista_PDF_Doc/2011/Artigo_07.pdf $>$. Acesso em: 28 out. 2014.

BARBETTA, P. A. Estatística aplicada às ciências sociais. 5. ed. Santa Catarina: UFSC, 2002.

BARROS, D. M. V. Educação a distância e as novas demandas ocupacionais. Revista Tecnologia Educacional, Rio de Janeiro, v. 30, n. 156, p. 1226, jan./mar. 2002.

BELLONI, M. L. Educação a distância. 5. ed. Campinas: Autores Associados, 2008. (Coleção Educação contemporânea).

BELLONI, M. L. O que é mídia-educação. 2. ed. São Paulo: Autores Associados, 2006.

BRASIL. Decreto no 5.622, de 19 de dezembro de 2005. Regulamenta o art. 80 da Lei no 9.394, de 20 de dezembro de 1996, que estabelece as diretrizes e bases da educação nacional. Disponível em: $<$ http://www.planalto.gov.br/ccivil_03/_ato20042006/2005/decreto/d5622.htm>. Acesso em: 12 maio 2015 .

BRASIL. Decreto no 5.800, de 8 de junho de 2006. Dispõe sobre o Sistema Universidade Aberta do Brasil-UAB. Disponível em: <http:// www.planalto.gov.br/ccivil_03/_ato20042006/2006/decreto/d5800.htm>. Acesso em: 12 maio 2015. 
COORDENAÇÃO DE APERFEIÇOAMENTO DE PESSOAL DE NÍVEL SUPERIOR - CAPES (Ed.). Universidade aberta do Brasil: o polo de apoio presencial. 2015. Disponível em: <http://uab.capes. gov.br/index.php/polos-841937/modelo-de-polo>. Acesso em: 10 maio 2015.

COSTA, K. S.; FARIA, G. G. EAD: sua origem histórica, evolução e atualidade brasileira face ao paradigma da educação presencial. In: CONGRESSO INTERNACIONAL DE EDUCAÇÃO A DISTÂNCIA, 14., 2008, Santos. Anais... Santos, 2008.

CUNHA, L. A. Educação e desenvolvimento social no Brasil. 9. ed. Rio de Janeiro: F. Alves, 1986. (Educação em questão).

FORACCHI, M. M.; PEREIRA, L. Educação $e$ sociedade: leituras de sociologia da educação. 9. ed. São Paulo: Comp. Ed. Nacional, 1978. (Ciências Sociais, 16).

FREIRE, P.; SHOR, I. Medo e ousadia: o cotidiano do professor. Rio de Janeiro: Paz e Terra, 2013. Disponível em: <https://books.google.com.br/ books?id=_rzNAgAAQBAJ\&pg=PT56\&dq=>. Acesso em: 20 abr. 2015.

GIL, A. C. Como elaborar projetos de pesquisa. 4. ed. São Paulo: Atlas, 2008.

GIUSTA, A. S.; FRANCO, I. M. (Org.). Educação à distância: uma articulação entre a teoria e a prática. Belo Horizonte: PUC Minas Virtual, 2003.

GONZÁLEZ, M. Fundamentos da tutoria em educação a distância. São Paulo: Avercamp, 2005.

LITTO, F. M.; FORMIGA, M. (Org.). Educação a distância: o estado da arte. São Paulo: Pearson, 2009.

LOBO NETO, F. J. S. (Org.). Educação a distância: referências e trajetórias. Rio de Janeiro: Plano, 2001.

MAIA, C.; MATTAR, J. $A B C$ da EaD: a educação a distância hoje. São Paulo: Pearson, 2007.

MARCONI, M.deA.; LAKATOS, E. M.Fundamentos da metodologia cientifica. São Paulo: Atlas, 2003.
MOORE, M.; KEARSLEY, G. Educação a distância: uma visão integrada. São Paulo: Thomson, 2007.

MORAN, J. M.; VALENTE, J. A. Educação a distância: pontos e contrapontos. São Paulo: Summus, 2011. Disponível em: <https://books. google.com.br/books?id=5HymAgAAQBAJ\&pg= PT68\&dq=>. Acesso em: 18 jun. 2015.

MORESI, E. Metodologia da pesquisa. Trabalho científico (Programa de Pós-Graduação Stricto Sensu em Gestão do Conhecimento e Tecnologia da Informação) Universidade Católica de Brasília, 2003.

NUNES, I. B. A história da EAD no mundo. In: LITTO, F.; FORMIGA, M. (Org.). Educação a distância: o estado da arte. São Paulo: Pearson Education do Brasil, 2009. p. 2-8.

PRETTO, N. L. Desafios para a educação na era da informação: o presencial, a distância, as mesmas políticas e o de sempre. In: BARRETO, R. G. (Org.). Tecnologias educacionais e educação a distância: avaliando políticas e práticas. Rio de Janeiro: Quartet, 2003. p. 29- 53.

SANTOS, A. I. O conceito de abertura em EaD. In: LITTO, F. M.; FORMIGA, M. (Org.). Educação a distância: o estado da arte. São Paulo: Pearson Education Brasil, 2009. p. 290-296.

SANTOS, I.; CLOS, A. C. Pesquisa quantitativa e metodologia. In: GAUTHIER, J. H. M. et al. Pesquisa em enfermagem: novas metodologias aplicadas: Rio de Janeiro: Guanabara Koogan, 1998.

SANTOS, Silvio Coelho. Um esquema para a educação em Santa Catarina. Florianópolis: Edeme, 1970.

SILVA, A. C. R. Educação a distância e o seu grande desafio: o aluno como sujeito de sua própria aprendizagem. In: CONGRESSO INTERNACIONAL DE EDUCAÇÃO A DISTÂNCIA APRESENTAÇÃO DE TRABALHOS CIENTÍFICOS, 11., 2004, Salvador. Anais... Salvador, 2004. p. 1 - 13. Disponível em: $<$ http://www.abed.org.br/congresso2004/por/ htm/012-TC-A2.htm>. Acesso em: 18 jun. 2015. 
SOUZA, L. B. Educação superior a distância: o perfil do "novo" aluno sanfranciscano. Revista Brasileira de Aprendizagem Aberta e A Distância, São Paulo, v. 11, p. 1-13, 2012. Disponível em: $<$ http://www.abed.org.br/revistacientifica/Revista PDF_Doc/2012/artigo_02_v112012.pdf $>$. Acesso em: $\overline{2} 0$ jun. 2015.

TRIVIÑOS, A. Introdução à pesquisa em ciências sociais: a pesquisa qualitativa em educação. São Paulo: Atlas, 1995.

VERGARA, S. C. Projetos e relatórios de pesquisa em administração. São Paulo: Atlas, 2000. 
Machado, M. R.; et. al. 